\title{
Мутные зеркала нефтяной экономики
}

О.С. АНАШКИН, кандидат экономических наук, Национальный исследовательский университет «Высшая школа экономики», Москва. E-mail: oanashkin@hse.ru

Анализируются возможности получения данных, необходимых для анализа экономических результатов недропользования, из отчётов о деятельности вертикально интегрированных нефтяных компаний. Рассматривается информация, содержащаяся в некоторых специализированных базах данных. Обсуждаются тенденции раскрытия информации добывающих компаний, складывающиеся в мире.

Ключевые слова: вертикально интегрированная нефтяная компания, отчётность, прозрачность информации, месторождение

В 2015 г. минерально-сырьевой и энергетический секторы экономики России обеспечили около 25-30\% ВВП страны, 60\% доходов федерального бюджета, 75\% экспортных доходов, 35\% инвестиций в основной капитал ${ }^{1}$. При этом примерно 80\%-вклад нефтегазового комплекса. Доминирующее положение в нём в настоящее время занимают несколько холдинговых структур вертикально интегрированных компаний, объединяющих под своим контролем всю цепочку производственного процесса: поиск и добычу сырья, его переработку, сбыт конечной продукции. Поэтому их роль в отечественной экономике настолько значительна, что экономические перспективы страны во многом зависят от успешного развития этих компаний.

Отсюда с очевидностью вытекает необходимость регулирования деятельности таких компаний с тем, чтобы обеспечить её соответствие интересам страны. К тому же недра в России являются государственной собственностью, и компании, которым предоставлено право пользоваться ею, должны делать это эффективно. Государственное регулирование действительно сможет способствовать достижению указанных целей, только если оно будет опираться на результаты исследований, изучающих фактическое положение дел. В свою очередь, для таких работ

${ }^{1}$ Оценки В.А. Крюкова с учётом результатов, полученных Экономической экспертной группой (Е. Гурвич), Внешэкономбанком (А. Клепач), Институтом народнохозяйственного прогнозирования РАН (А. Широв). 
нужна полная информация о деятельности компаний на каждом из разрабатываемых ею месторождений, позволяющая строить модели для проведения необходимых технологических и экономических оценок и получения на их основе выводов. А тут ситуация довольно печальная. Её рассмотрению применительно к вертикально интегрированным нефтяным компаниям (ВИНК) и посвящена данная статья.

\section{Информационный голод}

Анализу развития вертикально интегрированных нефтяных компаний в России посвящено большое количество публикаций (например [Алекперов, 1996; Густафсон, 2017; Крюков, Шафраник, 2016]), где подробно рассматривается их история, начиная с первых лет приватизации. Согласно этим публикациям, завершение становления ВИНК и более-менее окончательного раздела деятельности в нефтяной отрасли можно отнести к началу 2000-х годов.

К этому времени вставшие на ноги ВИНК получили возможность осмотреться и определиться с приобретением новых месторождений, усиливающих их рыночные позиции. Большинство прошедших тяжелый путь становления и выживания малых нефтяных компаний, уставших от борьбы за существование и недостатка средств, созрели для продажи своего бизнеса за достойное вознаграждение. А что могло быть лучше для ВИНК, чем купить готовую компанию с неплохими месторождениями в активах, работающую на той же территории (о других способах приобретения таких компаний умолчим)?!

Это было время, когда имелась возможность получить доступ к бухгалтерской отчетности или заключениям независимых аналитиков (аудиторов), необходимым таким компаниям для определения своей стоимости. А поскольку их деятельность происходила в основном на одном-двух месторождениях, то и основные показатели этих месторождений становились известными и поддавались анализу. Приложив немного усилий, можно было запросить и получить в пользование необходимые данные, позволяющие строить модели для оценки деятельности предприятия (месторождения) как отдельно взятого объекта (проекта). Анализ такой информации позволял делать оценки принимаемых решений о приобретении активов и дальнейшем управлении ими.
Однако этот период оказался очень непродолжительным. Большинство привлекательных и перспективных малых компаний очень скоро были интегрированы в ближайшие дочерние компании основных ВИНК, а результаты их деятельности растворились во внутренних отчётах. На поверхности остались лишь показатели в обобщённом виде, в лучшем случае по отдельной дочерней компании головной ВИНК.

Сегодня, чтобы получить доступ к первичной информации о работе ВИНК на том или ином месторождении, мало даже работать в центральном аппарате ВИНК: нужно быть сотрудником экономического подразделения, курирующего деятельность дочерней компании, которая разрабатывает месторождение. Во многих случаях и этого может оказаться недостаточно, потребуется поездка на само месторождение, чтобы выяснить возможности получения доступа к первичной информации и убедиться в правильной её интерпретации в автоматизированной системе учёта ВИНК, если таковая имеется. По опыту автора, количество людей, имеющих возможность получить доступ к такой информации, очень ограничено, так что «непосвящённому» добыть её практически нереально. Как ведется работа по повышению эффективности работы отдельных месторождений (залежей, пластов) службами компаний, включая экономические, скрыто от стороннего наблюдателя.

Следует, правда, сказать, что в очень редких случаях коекакая информация появляется. Иногда для освоения новых месторождений в ВИНК создаются отдельные дочерние компании. Например, в составе НК «Роснефть» функционируют ОАО «Сузун» и ООО «Тагульское», разрабатывающие Сузунское и Тагульское месторождения на севере Красноярского края; для разработки Ванкорского месторождения было создано АО «Ванкорнефть». Когда отчётность по их деятельности публикуется, особенно на начальном этапе освоения месторождений, появляется возможность проведения хоть какой-то оценки успешности работы на соответствующих месторождениях.

Что же касается государственных органов, то со стороны кажется, что их поведение и организация работы сохраняют инерцию советских времён. Они, похоже, продолжают опираться на приобретённый тогда опыт взаимодействия с крупными объединениями. Статистическая отчётность остаётся с тех 
времён практически в неизменном виде (правда, небольшие новации всё же есть). И хотя часть показателей имеет отношение к деятельности на отдельных месторождениях, как раз эта информация имеет статус конфиденциальной, а значит, недоступна для исследователей.

Как используется эта информация при разработке государственных нормативных документов, связанных с управлением и регулированием деятельности нефтяной отрасли, скрыто от широкой аудитории заинтересованных специалистов. Какие при этом применяются математические методы, с помощью которых, например, разрабатываются программы стратегического развития? Как учитываются в этих программах влияние инноваций, накопленных знаний, рост квалификаций специалистов и т.п.? Каким образом отслеживаются затраты на выполнение типовых производственных операций, трансакционные издержки? Всё это остаётся тайной для избранных.

В таких условиях исследователи изобретают собственные подходы для решения аналогичных задач. Например, строят трендовые модели по тем скудным фактическим данным, которые у них имеются, с учётом небольших отклонений, обусловленных возможными изменениями в технологических подходах, объектах и т.д. Но это не лучший путь для серьёзных научных исследований. Другой путь, по которому идёт большинство исследований - использование в качестве аналогов зарубежных проектов (месторождений), информация по которым намного полнее и доступнее.

\section{Что имеем?}

Рассмотрим, какая же информация имеется в наличии. Автором был проведен анализ практически всех показателей, содержащихся в первичных формах статотчётности о деятельности нефтегазодобывающих компаний (27 форм), а также показателей из сводных форм, публикуемых Росстатом и «ЦДУ ТЭК»².

2 «ЦДУ ТЭК»- федеральное государственное бюджетное учреждение «Центральное диспетчерское управление топливно-энергетического комплекса». Оно осуществляе круглосуточный сбор и обработку первичной оперативной информации производственного характера о состоянии всех отраслей ТЭК. Формируемые «ЦДУ ТЭК» статистические отчёты предоставляются за плату, их перечень по нефтяной промышленности приведён на URL: http://www.cdu.ru/catalog/operative data/section. php? SECTION ID=117
Доступными (свободно или за плату) являются только сводные формы, показатели в которых получены агрегированием данных из отчётности отдельных компаний. Более того, эти показатели не позволяют делать конкретные и обоснованные экономические выводы, например, об успешности эксплуатации разрабатываемых месторождений. Что же касается первичной отчётности компаний, то в ней только две формы имеют непосредственное отношение к конкретным месторождениям и их залежам.

Первая из них носит длинное название: № 6-ГР «Сведения о состоянии и изменении запасов и ресурсов категории $\mathrm{D}_{0}$ нефти, газа, конденсата, этана, пропана, бутанов, серы, гелия, азота, углекислого газа, примесей ванадия и никеля в нефти» ${ }^{3}$. Это годовая форма федерального статистического наблюдения, в которой два раздела: в первом указаны сведения о состоянии и изменении запасов нефти и содержании в ней отдельных химических элементов; во втором представлены данные о состоянии и изменении ресурсов нефти и свободного газа категории $\mathrm{D}_{0}$.

По распределённому фонду недр информация представляется владельцами лицензий на разработку месторождений (компаниями или физическими лицами), по нераспределенному фонду недр - территориальными органами Федерального агентства по недропользованию (Роснедра). Сведения о состоянии и изменении запасов предоставляются отдельными отчётами по каждому виду полезного ископаемого.

В отчёте приводятся значения текущих запасов углеводородного сырья по категориям от А до $\mathrm{C}_{2}$ (в соответствии с российской классификацией запасов и ресурсов нефти и горючих газов) по состоянию на 1 января отчётного года, которые должны совпадать с данными государственного баланса запасов полезных ископаемых РФ за прошедший год, и по состоянию на 1 января года, следующего за отчётным. В форме содержатся показатели, отражающие параметры разработки месторождения (залежи), параметры пласта и качественные характеристики добываемых нефти, газа и конденсата. Кроме того, к каждому отчёту по форме № 6-ГР должна быть приложена пояснительная записка с обоснованием причин изменения состояния запасов за отчётный

${ }^{3}$ URL: http://www.gkz-rf.ru/sites/default/files/docs/prikaz rosstata no844 ot 21.12.16 utverzhdenie novoy formy 6-gr.pdf 
год, включая данные по добыче нефти, газа (свободного, газовых шапок, растворённого) и попутных полезных компонентов.

В инструкции по заполнению формы указан способ проверки только правильности перехода от данных текущего года к следующему, но не определён сам механизм получения исходных данных и проверки правильности его применения. Поэтому невозможно его воспроизвести даже для элементарной проверки.

Ни в показателях формы, ни в пояснительной записке не нашлось места для отражения ни фактических, ни расчётных экономических результатов, позволяющих подтвердить правильность принятых (или обоснованность принимаемых) решений по разработке месторождения. Единственный показатель, который можно отнести к экономическим, - это показатель рентабельно извлекаемых запасов.

Но самое главное, содержащаяся в форме № 6-ГР информация является конфиденцุиальной, а значит, практически недоступной сторонним исследователям.

Вторая отчётная форма, заслуживающая внимания, находится в стадии апробации, она разработана в рамках совершенствования квартальной отчетности для «ЦДУ ТЭК» и касается добычи нефти из трудноизвлекаемых запасов и льготируемой добычи углеводородного сырья. О конфиденциальности этой формы пока нигде не говорится, но в перечне форм «ЦДУ ТЭК» информации о возможности её приобретения нет. Форма была разослана по всем 195 компаниям, акционерным обществам и предприятиям, осуществляющим нефтедобычу на территории страны.

В разделе 1 рассматриваемой формы - «Добыча нефти трудноизвлекаемых запасов» - приводятся данные о добыче нефти из таких запасов с начала разработки и за отчётный квартал, а также об объёмах инвестиций с начала отчётного года. Отчёт составляется в разрезе залежей/пластов. К экономике здесь имеет отношение единственный показатель: «Объёмы фактически понесённых инвестиций с начала отчётного года, млн руб.». Он позволяет (по крайней мере, теоретически) определить удельный объём инвестиций - на тонну добытой нефти.

В разделе 2 формы - «Льготируемая добыча углеводородного сырья» - содержится информация о добытой нефти с начала получения льготы и за отчётный квартал, а также об объёмах инвестиций с начала отчётного года по месторождениям /объектам разработки/ лицензионным участкам, по которым льготы либо фактически получены, либо их получение заложено в планы компании. Отчёт составляется в разрезе залежей /пластов/ месторождений/ лицензионных участков. Применение льгот осуществляется согласно порядку и перечню, установленным соответствующими пунктами ст. 342 и 343 Налогового кодекса РФ.

Содержащиеся в этом разделе данные позволяют определить количество льгот, которые получил недропользователь (компания) за время разработки определённых залежей и месторождений, а также об объёмах инвестиций на них за этот период. Тут тоже только один экономический показатель - опять же, объём инвестиций.

Отметим, что ещё совсем недавно в Налоговом кодексе почти не было статей, посвящённых льготам при добыче нефти. Сегодня же они стремительно размножаются. Если эта тенденция сохранится, то скоро мы столкнемся с ситуацией, когда вопрос о применении схемы налогообложения будет решаться для каждого месторождения индивидуально.

Однако трудноизвлекаемость, по мнению автора, - понятие не столько геологическое, сколько экономическое. В работе [Анашкин, Рохлин, 2015] было впервые предложено ввести в определение трудноизвлекаемых запасов углеводородного сырья экономический критерий. Суть этого предложения в том, что любое месторождение, даже самое успешное, доживает до периода, когда вся оставшаяся в нём нефть становится трудноизвлекаемой, т.е. экономически не выгодной для добычи. Таким образом, основным критерием выбора лучшего варианта освоения запасов может служить показатель эффективности проекта (практически аналогичный показателю общественной эффективности ${ }^{4}$, учитывающий интересы как государства, так и недропользователя.

Кроме официальной отчётности компаний, есть ещё один возможный источник информации - специализированные базы данных. Рассмотрим две наиболее популярные и развитые.

UCube компании Rystad Energy - это глобальная база данных и одновременно аналитический инструмент по международной нефтегазодобывающей индустрии, основанный на разнообразных

\footnotetext{
${ }^{4}$ Методические рекомендации по оценке эффективности инвестиционных проектов и их отбору для финансирования. М.: Экономика, 1994.
} 
данных по существующим месторождениям нефти и газа. База данных UCube представляет собой интегрированную среду, данные в которой можно просматривать в различных разрезах, например, по географической принадлежности, морским либо континентальным месторождениям, по этапам разведки или разработки месторождения, по типам углеводородов (включая нетрадиционные). Информация в базе организована «снизу вверх», что позволяет агрегировать данные по месторождениям до более высоких уровней: компании, страны, региона; можно также визуализировать полученный результат по любым имеющимся в базе показателям. UCube содержит информацию по более чем 65 тыс. активов (месторождений) и 3,2 тыс. компаний.

Информация в UCube представляет собой сочетание как фактических, так и смоделированных данных, а соотношение между ними прямо зависит от прозрачности добывающей отрасли в различных странах. Фактические данные берутся из всевозможных открытых источников, главным образом - из отчётности компаний и государственных организаций. Получаемые таким образом фактические сведения детально анализируются, приводятся в единообразный вид, в отдельных случаях - корректируются с помощью экспертных оценок. Далее информация калибруется по уровням: суммарно по компаниям, странам и т.д., что делает UCube полностью согласованным глобальным инструментом. Но так как данные по российским месторождениям, разрабатываемым отечественными компаниями, получают из открытых источников, их не может быть больше и они не могут быть точнее, чем в отчётных формах, представляемых компаниями в государственные органы.

Компанией Ingenix Group, входящей в группу Газпромбанк, создана база данных стоимости свыше 1800 объектов нефтегазового строительства. Она является информационной основой разработанного компанией программного комплекса для детального моделирования стоимости разработки, обустройства и эксплуатации нефтегазовых месторождений, а также оценки эффективности капиталовложений 5 . Этот комплекс поставляется добывающим компаниям, где может использоваться в рамках корпоративной информационной системы. Информация, содер-

${ }^{5}$ URL: http://ingenix-group.ru/services/software/ жащаяся в рассматриваемой базе данных, доступна только специалистам Ingenix Group и компаний, приобретших её продукт. Посторонним вход воспрещён. Таким образом, возможность проведения независимой оценки и анализа результатов, получаемых по конкретным месторождениям, отсутствует.

А доступная для исследовательской работы информация недостаточна для построения даже простейших моделей, позволяющих получить элементарные оценки экономического состояния разработки конкретных месторождений. И без организации доступа к необходимой информации экспертное сообщество не может участвовать в процессе комплексной оценки и совершенствования государственного управления экономикой недропользования.

Добывающие компании осознают необходимость сбора такой информации, позволяющей им самим анализировать происходящие в них процессы, в том числе и с экономической точки зрения. Однако отнюдь не склонны такой информацией делиться, даже с государственными органами, используя её лишь в своих корпоративных интересах. Один из результатов такой закрытости - регулярное возникновение коалиций добывающих компаний, «проталкивающих» различные условия для получения «обоснованных» льгот.

Вот один из примеров. Министр энергетики А. Новак сообщил, что правительство скоро примет окончательное решение по законопроекту о льготах для обводнённых месторождений, и он вступит в силу с 1 января 2018 г. Законопроект предусматривает выдачу льготы обводнённым месторождениям в размере $50 \%$ от ставки налога на добычу полезных ископаемых 6 . А министр финансов А. Силуанов заявляет, что предоставление льгот для обводнённых месторождений нефти не обосновано с экономической точки зрения; Минфин по-прежнему выступает против их введения и оценивает возможные потери бюджета от них в 130 млрд руб. в год7. Будь информация обо всех месторождениях и деятельности компаний на них доступна независимым экспертам, подобные споры невозможно было бы даже представить.

В настоящее время этот механизм сведён к индивидуальному подходу. Так, льгота по НДПИ закреплена лишь за Самотлорским месторождением

${ }^{6}$ Новак: обводненные месторождения нефти могут получить льготу уже в 2018 году // Ведомости. 2017. 6 июля. URL: https://www.vedomosti.ru/business/news/2017/07/06/712523novak

Минфин оценил потери бюджета от льгот для обводненных месторождений в 130 млрд руб. в год // TACC. 2017. 10 июля. URL: http://tass.ru/ekonomika/4402272 
«Роснефти»: 6 октября 2017 г. Минфин сообщил, что НДПИ для этого месторождения будет снижаться на 35 млрд руб. ежегодно в течение десяти лет, а «Роснефть» взяла на себя обязательства по увеличению добычи на Самотлоре, но деталей не раскрыла. Другие нефтяные компании подобных льгот не получили. Естественно, они тут же обратились к главе правительства, поставив вопрос об отмене такой налоговой дискриминациив ${ }^{8}$.

Казалось бы, подобные вопросы должны решаться просто до тех пор, пока информация о месторождениях и их разработке компаниями не будет доступна для проведения независимой экономической экспертизы, государство не должно даже рассматривать вопросы о предоставлении каких-либо льгот для отдельно взятых месторождений ${ }^{9}$ Все необходимые оценки можно было бы провести за один-два года только силами вузов соответствующего профиля, не говоря уже об академических институтах. Но, видимо, правительство пока не понимает, зачем это нужно. Хотя прецеденты есть: в 2013 г. был снят гриф секретности с баланса нефтяных запасов ${ }^{10}$ [9]. Это позволило увеличить привлекательность отечественного топливно-энергетического комплекса для зарубежных инвесторов, а российским компаниям - облегчить прохождение международного аудита. Тут понимание пришло, президент страны даже назвал такую секретность «явным анахронизмом» ${ }^{11}[10]$.

Однако, получив доступ к имеющемуся на 2012 г. перечню всех месторождений, мы смогли увидеть лишь информацию о географическом расположении, его типе, названии лицензии и сроках её действия, стадии освоения, имени недропользователя, а также объёмные характеристики добычи и запасов по категориям на начало и конец отчётного года. Никаких экономических показателей среди этих данных нет.

${ }^{8}$ Конкуренты «Роснефти» пожаловались Медведеву на налоговую дискриминацию // РБК. 2017. 17 октября. URL: https://www.rbc.ru/business/17/10/2017 59e0d5da9a794719ffa11bbd

Ещё одним рычагом, побуждающим компании раскрывать информацию, может быть продление лицензий на разработку месторождений: нет информации -нет продления.

${ }^{10}$ Постановление Правительства Российской Федерации от 5 июля 2013 г. № 569 «О внесении изменений в постановление Правительства Российской Федерации от 2 апреля 2002 г. № 210» // Собрание законодательства Российской Федерации. 2013. № 28. Ст. 3834

1 В. Путин поручил «рассекретить» баланс нефтяных запасов РФ // РБК. 2013 13 фев. URL: http://www.rbc.ru/economics/13/02/2013/5704037d9a7947fcbd445ab6

\section{А как в мире?}

До недавнего времени мир двигался в сторону всё большей информационной открытости. В 2003 г. родилась «Инициатива прозрачности в добывающих отраслях»-общемировой стандарт публикации информации нефтяной, газовой и горнодобывающей отраслей промышленности, способствующий открытому управлению и подотчётности в секторах нефтяных, газовых и минеральных ресурсов ${ }^{12}$. В поддержку этой инициативы ряд развитых стран, в том числе США, страны ЕС и Канада, законодательно утвердили требования о раскрытии компаниями информации о фискальных условиях и платежах за недропользование, включая разведку и добычу. Так, в 2016 г. Комиссия по ценным бумагам и биржам США одобрила требования об обязательном раскрытии информации сырьевыми компаниями.

Однако в последнее время началось попятное движение. Американские компании увидели в таком регулировании угрозу, ссылаясь на то, что подконтрольные государству крупные компании (такие как российская «Роснефть» или китайская CNOOC), с которыми им приходится конкурировать на мировом рынке, могут получить конкурентное преимущество: они владеют львиной долей запасов, но требования к отчётности у них другие. В своих предвыборных выступлениях Д. Трамп давал обещания существенно ослабить госрегулирование нефтяного и горнорудного секторов. А теперь стал их выполнять, пользуясь поддержкой пришедших к власти республиканцев, которые тоже считают, что установленное предыдущей администрацией требование обременительно для экономики США. И в феврале 2017 г. Сенат США принял резолюцию об отмене жёстких мер регулирования для американских ресурсодобывающих компаний, обязывающих их раскрывать информацию о налогах и других платежах перед иностранными правительствами ${ }^{13}$.

Каковы последствия этого, пока можно только предполагать. Отмена обязательной отчётности перед иностранными правительствами для американских компаний - включая таких гигантов, как Exxon и Chevron - скорее всего, ударит по европейским

\footnotetext{
${ }^{12}$ URL: https://eiti.org/ru

${ }^{13}$ США отменят обязательную отчётность о платежах для ресурсодобывающих компаний // Reuters. 2017. 3 фев. URL: http://ru.reuters.com/article/businessNews/ idRUKBN15I1C4
} 
и канадским компаниям, которые по-прежнему будут подчиняться довольно жёстким требованиям (в том числе и в своих странах).

Возникнут трудности в установлении разумных мер регулирования в отдельно взятых странах, которые позволили бы найти баланс между прозрачностью и поддержанием конкурентоспособности среди работающих в стране компаний. Даже зная исходные условия и некоторые технические результаты основной деятельности каждой из компаний, государственные структуры страны всё равно не будут обладать полной информацией для оценки эффективности мероприятий, связанных с добычей сырья. Нельзя будет создать предпосылки для справедливой конкуренции между компаниями из-за отсутствия одинаковых условий и месторождений.

Наиболее крупные компании на время получат возможность использовать нерыночные формы (неконкурентные возможности) ведения бизнеса для достижения доминирующего положения в отдельных регионах. Но, думается, в конечном итоге большее преимущество получат всё же те компании, которые не побоятся начать раскрывать информацию о проводимых ими мероприятиях с обоснованной оценкой экономических результатов (и даже обеспечат участие владельца прав на недра в справедливом распределении этих результатов).

Там, где правительства стран, в которых ведут добычу иностранные компании, будут регулярно проводить анализ того, сколько средств вложено в разработку недр и что в результате получила от этого страна, возникнет необходимость в создании отчётности, содержащей необходимые для такого анализа данные, но без раскрытия дополнительных деталей.

Противоречивость ситуации с раскрытием информации сырьевыми компаниями должна привести к пониманию, что она не согласуется с мировой тенденцией к увеличению прозрачности нефтяной отрасли. И можно надеяться, что наметится путь к исправлению этой ситуации. Идеальным решением было бы присоединение к «Инициативе прозрачности в добывающих отраслях». Но у разных стран могут быть различные подходыот установления обязательных правил отчётности для всех до индивидуальных договоров по каждому объекту. Не исключено, что некоторые страны станут отдавать предпочтение группам мелких компаний, соглашающимся на любые условия, а не транснациональным монстрам.

\section{Что делать?}

Итак, публикуемая сегодня отчётность нефтедобывающей отрасли не позволяет отслеживать или даже примерно прогнозировать формирование и движение денежных потоков ВИНК, порождаемых деятельностью на отдельных месторождениях. Эти отчёты почти не содержат экономической информации, запутаны, непрозрачны не только для фискальных органов, но зачастую и для инвесторов. Такую политику необходимо кардинально менять.

Только открытость и доступность информации о деятельности компаний, отчётность об исполнении условий лицензий на месторождения, прозрачность достигнутых результатов, включая экономические, могут стать залогом успешного регулирования экономики недропользования в стране. Мутные зеркала существующей отчётности, в которых едва отражается реальная ситуация в отрасли, заставляют исследователей и экспертов изобретать свои методы её интерпретации. Результаты можно сравнить с отражениями уже не в мутных, а в разнообразных кривых зеркалах собственного изготовления.

Какая же информация нужна? Если кратко, должна быть доступна информация, которая позволила бы рассматривать каждое месторождение (залежь) как самостоятельный проект и давала возможность проводить независимую оценку его технологических и экономических показателей.

Следует сказать, что такая информация нужна и самим ВИНК. Изменившиеся в последнее время условия функционирования отечественных нефтяных компаний (в частности, падение цен на нефть и санкции, введённые против российской нефтяной отрасли) заставляют управленческий персонал находить новые возможности для работы в нестабильной и неопределённой внешней среде. Необходимо чётко определять глобальную перспективу бизнеса. Единая стратегия управления и ориентированность на ключевые факторы успеха ВИНК требуют обращать внимание не только на консолидацию финансовых результатов дочерних компаний, но и на результаты деятельности на каждом отдельном месторождении. Эти задачи невозможно решать без наличия полной информации о состоянии ресурсной базы, условиях разработки объектов, учёта внедрения технологических инноваций и большого количества иной первичной информации. 
Таким образом, необходимо проведение реформ, направленных на открытие первичной информации. Это позволит создать информационную среду, способствующую равноправной конкуренции нефтедобывающих компаний, независимо от их размеров и форм собственности. Только равноправная, прозрачная конкуренция между компаниями с разумным контролем государством всех условий, в которых она осуществляется, способна привести к долговременному эффективному использованию богатейших природных ресурсов нашей страны.

\section{Литература}

Алекперов В. Ю. Вертикально интегрированные нефтяные компании России. М.: АУТОПАН, 1996.

Анашкин О.С., Рохлин С.М. Интегральные показатели экономической эффективности при формировании сырьевой базы углеводородов России // Недропользование XXI век. 2015. № 7. С. 130-136.

Густафсон T. Колесо фортуны: битва за нефть и власть в России. М.: Альпина Паблишер, 2017.

Крюков В.А., Шафраник Ю.К. Нефтегазовый сектор России: трудный путь к многообразию. М., 2016.

Статья поступила 23.01.2018.

\section{Summary}

Anashkin O.S., National Research University "Higher School of Economics", Faculty of World Economy and International Affairs, Moscow

\section{Cloudy Mirrors of the Oil Economy}

This article considers possibilities of obtaining data needed for analysis of economics results of mining from reports of vertically integrated oil companies. It also describes information contained in some special-purpose data bases. World trends in information disclosure of oil-producing companies are discussed.

Vertically integrated oil company; reporting; transparency of information; oilfield

\section{References}

Alekperov V. Ju. (1996). Vertikal'no integrirovannye neftjanye kompanii Rossii. Moscow, AUTOPAN Publ. (In Russ.).

Anashkin O.S., Rohlin S.M. (2015). Integral'nye pokazateli jekonomicheskoj jeffektivnosti pri formirovanii syr'evoj bazy uglevodorodov Rossii. Nedropol'zovanie XXI vek. No 7. Pp. 130-136. (In Russ.).

Gustafson T. (2017). Koleso fortuny: bitva za neft' i vlast' v Rossii. Moscow, Al'pina Pablisher. (In Russ.).

Krjukov V.A., Shafranik Ju.K. (2016). Neftegazovyj sektor Rossii: trudnyj put' k mnogoobraziju. M. (In Russ.). 